\title{
THE CLASSIFICATION OF DEPRESSION
}

\author{
E.S. PAYKEL \\ Department of Psychiatry, St George's Hospital Medical School, London SW17 0RE, UK
}

\section{Current concepts of classification}

The classification of depression is a broad topic, sufficient to keep armies of psychiatrists disputing happily for years. This paper will focus particularly on the concept of anxious depression, and its relevance to other classifications. I will not deal directly with the distinction between anxiety and depression, which is covered elsewhere in this session. I am more concerned with the place of anxiety in the classification of samples already defined as fitting criteria for depression.

To review briefly current ideas regarding depressive classification, the last decade has not produced much greater unanimity than previously. Andreasen (1982) has recently reviewed this topic. She points out the complexity of the existing official classification systems, particularly the 9th edition of the ICD and the American DSM-III. The ICD has up to eight possible categories for patients showing depressed mood. One of these, affective psychoses (296), has many subcategories. DSM-III has different complexities, shown in Table 1 , and rendered more puzzling by its abandonment of traditional nomenclature. The affective disorders are divided into two main groups, major affective disorders and other specific affective disorders, with a third group of atypical affective disorders which are those not quite fitting the other criteria. Major affective disorders are themselves divided into bipolar disorders and major depression. Each has subtypes. The word neurotic does not appear but depression can be with or without psychotic features (i.e., delusions, hallucinations or stupor) and similarly for melancholia (corresponding to the endogenous symptom pattern). The other specific affective disorders include two varieties of chronic persistent mood disorder, cyclothymic disorder (with depressive and hypomanic swings) and dysthymic disorder (persistent mild depression which may be intermittent). In addition schizoaffective disorder has a separate category and there is also a category for adjustment disorders with depressed mood.

After these complexities it is a relief to turn to the usual clinical classifications. There is no doubt that two classifications have fairly universal acceptance both clinically and in research. The first is the separation into the bipolar disorders and unipolar disorders. It is interesting that this
Table 1 Classification of affective disorders in DSMIII

Major affective disorders

Bipolar disorder

Manic

Depressed

Mixed

Major depression

Single episode or recurrent

With or without melancholia

With or without psychotic features

Other specific affective disorders

Cyclothymic disorder

Dysthymic disorder

Atypical affective disorders

Atypical bipolar disorder

Atypical depression

separation runs counter to Kraepelin's view that all the affective disorders belong under a single heading of manic-depressive illness. The recognition that those cases showing mania are different and can be separated off really depends on the work of Perris (1966) and Angst (1966). It has turned out to be a profitable distinction accompanied by genetic differences; hints of biological differences in such aspects as augmentation of the average visual evoked response, platelet MAO and urinary MHPG; differences in prognosis with a greater tendency to recurrence in bipolars; and probably a better response to lithium prophylactically and in the acute treatment of depression (Perris, 1982).

However, bipolars are uncommon and most depressions are unipolar. Here the familiar psychotic/neurotic or endogenous/reactive distinction still seems the most useful although some decry it and all admit that its outlines are fuzzy. There is one important recent issue. The concept of endogenous or psychotic depression is complex, suggesting that such depressions show not only absence of a precipitant stress, but also the presence of characteristic symptoms, such as greater severity, psychomotor retardation or agitation, guilt, delusions, morning worsening, early morning wakening. Several recent studies employing careful life event interviewing, have indicated that the link between the life event side of the equation and the symptom pattern side is weak (Paykel, 1982). In these studies there was only a very weak tendency 
for depressions with the endogenous symptom pattern to show less life stress than neurotic depressions. The majority of depressions showed evidence of preceding life event stress. It is probably best to take the American view, laying emphasis on the endogenous symptom pattern, similar to van Praag's concept of vital depression (van Praag et al., 1965) rather than on absence of life stress. The symptom pattern does seem to correlate to some extent with response to tricyclic antidepressants and particularly, when severe, with good response to ECT.

Some other classifications are of research interest. The St. Louis classification divides affective disorders into primary and secondary, and in Winokur's elaboration of it further divides unipolar primary depression into pure depressive disorder with a family history of depression only; depression spectrum disease where there is a family history of alcoholism, anti-social personality, hysteria or drug abuse; sporadic depressive disease where there is no family history (Andreasen, 1982). Secondly, there has been revived interest in atypical depression recently and I will return to it later. Thirdly there are a number of mathematically derived typologies. None of these classifications can be said to have come into universal clinical use.

\section{Anxiety and traditional classifications}

How does anxiety relate to these classifications? There have been relatively few investigations of symptom differences between bipolar and unipolar disorder (Perris, 1982). Existing studies do not suggest major differences but a recent paper reported less anxiety in bipolars (Katz et al., 1982). It should be kept in mind that the bipolar/unipolar distinction really concerns affective psychoses. Bipolars probably do tend to show a psychotic picture and if non-psychotic disorders are included in unipolar states the bipolar/unipolar distinction will tend to reflect the psychotic/neurotic one. Likewise there is little work suggesting symptom differences between primary and secondary depression, or between Winokur's three familial subtypes. However, previous anxiety neurosis will render a depression secondary, and there may be some overlap between depression spectrum disease and neurotic depression.

By contrast there is a good deal of work relating anxiety to what can be loosely referred to as the endogenous/neurotic distinction. It comes principally from the factor analytic studies. Table 2 summarizes the findings from eight studies which obtained factors reflecting the contrast between endogenous or psychotic and neurotic depression, and which included ratings of anxiety.
In three studies anxiety loaded strongly towards the neurotic end of a factor, and in two more it loaded weakly in this direction. In two studies it loaded weakly and in one study strongly in the psychotic direction. Two studies in which it loaded in the psychotic direction (Rosenthal \& Klerman, 1966; Rosenthal \& Gudeman, 1967a) differed from the remainder in having a unipolar endogenous factor without neurotic loadings rather than a bipolar factor. Rosenthal \& Gudeman (1967b) reported separately a second self-pitying factor and psychic and somatic anxiety loaded highly on this. The endogenous first factors in both studies could equally be interpreted as general severity factors. Rotation from a bipolar factor structure with anxiety at the neurotic pole can produce rather a similar endogenous factor (Paykel et al., 1971). Therefore the findings do suggest some relationship between presence of anxiety and a neurotic symptom pattern. However, the trend is not universal. In our own study (Paykel et al., 1971) although anxiety loaded in the direction of neurotic depression on the endogenous/neurotic factor it also emerged more strongly on a separate factor which contrasted the symptoms of anxiety with the symptoms of depression. Kendell (1968) found current anxiety not to load in either direction but previous anxiety symptoms loaded strongly in the neurotic direction. I have compromised and shown it in the table as a weak loading.

Table 2 Loadings of anxiety on endogenous/neurotic factors

\begin{tabular}{lc}
\hline Study & Loading \\
Carney et al. (1965) & + \\
Hamilton \& White (1959) & + \\
Paykel et al. (1971) & + \\
Kiloh \& Garside (1963) & $(+)$ \\
Kendell (1968) & $(+)$ \\
Kiloh et al. (1972) & $(-)$ \\
Rosenthal \& Klerman (1966) & $(-)$ \\
Rosenthal \& Gudeman (1967a) & -
\end{tabular}

+ Neurotic direction, - endogenous direction, ( ) loading $<0.30$

\section{Anxious depression}

A number of studies, reviewed by Gersh \& Fowles (1979), have in fact suggested that the presence of marked anxiety may provide a useful way of loosely identifying a group of depressions, and that this can predict treatment response. Such anxious depressives will tend, but not exclusively, to be in the neurotic end of the spectrum. Overall et al. (1966), using a multivariate procedure, divided inpatient depressives into three groups: retarded depressives, hostile depressives and anxious 
depressives. The anxious depressives were characterized by high scores on depressive mood, anxiety and tension. Thioridazine was found superior to imipramine in anxious depressives, while imipramine was superior in retarded depressives and hostile depressives did not do well with either drug. In subsequent studies these findings were replicated for perphenazine and amitriptyline (Hollister et al., 1966, 1967). These studies depended on inpatients in Veterans Administration Hospitals, a rather atypical group of male patients.

In a cluster analytic study (Paykel, 1971) we found four groups of depressives: psychotic depressives, anxious depressives, hostile depressives and young depressives with personality disorder. The patients with anxious depression were middleaged and had the highest score on psychic and somatic anxiety, depersonalization, obsessional symptoms and fatigue. They were also moderately severely depressed. They were a somewhat chronic, neurotic group with the highest number of previous episodes and high scores on the Maudsley Personality Inventory Neuroticism Scale. They tended particularly to be treated as day hospital patients. This classification was consistent with the psychotic/neurotic dichotomy, but suggested that neurotic depressives were diverse, comprising three groups. The anxious depressives were replicated later in the same sample using a different method of cluster analysis (Paykel \& Henderson, 1977).

In two successive series of patients treated with amitriptyline, anxious depressives responded poorly (Paykel, 1972; Prusoff \& Paykel, 1977). These were uncontrolled studies and although analyses of covariance suggested that the poor response was not simply due to the chronicity of anxious depressions, we could not be certain that we were demonstrating drug effects. It seemed possible that these anxious depressives might respond well to MAO inhibitors, but in two studies of phenelzine we have found no clear evidence of this (Paykel et al., 1979 and in press).

Anxiety, rated in our studies primarily by ratings of subjective psychic anxiety and somatic anxiety symptoms, must be distinguished from agitation, i.e., motor restlessness. In our cluster analysis it was not the anxious depressives but the psychotic depressives who scored highest on agitation. In Overall's studies (Overall \& Rhoades, 1982), more recently a separate agitated group has been separated off from the anxious depressives.

\section{Atypical depression}

Also related to anxious depression, is the concept of atypical depression. We have recently been interested in this diagnosis, which is closely bound up with response to MAO inhibitors. The first clear published description of atypical depression was in a study by West \& Dally (1959), working with Sargant at St. Thomas's Hospital. Responders to iproniazid were described as showing a syndrome including long illness, phobic and generalized anxiety, fatigue, evening worsening, hysterical symptoms, absence of self-reproach, of morning worsening and of early wakening, sometimes an impression of life-long inadequate personality although on close examination the premorbid personality was non-neurotic. There have been many subsequent papers.

When we came to look over the literature we were impressed that there were three different meanings which had been used by different authors when referring to atypical depression (Paykel et al., in press). The first one was that of marked anxiety and phobic symptoms, either accompanied by depression or assumed to have some relation to an underlying depression as indicated, for instance, by diurnal variation. This is much the same as anxious depression. It would include the influential views of Tyrer (1976) that MAO inhibitors are 'delayed psycho-stimulants' indicated for agoraphobia, anxiety neurosis, anergia and mixed anxiety depressions rather than pure depressions.

The second meaning is what Pollitt (1965) describes as reversed functional shift, i.e., depression with a diurnal pattern of evening worsening, insomnia of early rather than late kind, or increased sleep, increased appetite and weight, all in the opposite directions to the physiological changes said to characterize endogenous depression. In the USA Klein and colleagues (Quitkin et al., in press) who have reviewed the field and are undertaking a study of phenelzine, assign principal importance in their selection criteria to increased sleep, increased weight, and reactivity of mood.

A third meaning of atypical depression seems to be that of non-endogenous depression in general. This is a wider meaning than the usual implication of a specific subgroup. Also in the USA a systematic series of studies of MAO inhibitors have been carried out by Robinson, Nies and Ravaris. They have derived a diagnostic index for typical and atypical depression (Robinson et al., 1974), which assigns high weights for typical depression to suicidal ideation, weight loss, depressed mood, agitation, retardation, guilt, hallucinations and nihilistic delusions; high weights for atypical depression to psychic and somatic anxiety, initial insomnia.

These three meanings may identify different groups of patients. In the context of a drug trial in 
outpatient depressives we collected a large amount of data relevant to diagnosis, including specific diagnoses on many different subclassificatory systems (Paykel et al., in press). We examined the relationships between different diagnostic systems by Cramers' V, a non-parametric measure of association. Using measures of marked anxiety symptoms, reversed functional shift and nonendogenous depression, we found that these three criteria related poorly, and tended to select quite different patients. We had to conclude that the concept of atypical depression was imprecise. It would be better to specify which aspect was to be emphasized. Anxiety was marked in many of these subjects, confirming that anxious depression is common among outpatient depressives.

Our main interest was in the response to MAO inhibitors. Here previous studies have not been clear-cut. The best evidence that type of depression predicts response comes from controlled trials of phenelzine against placebo (Paykel, 1979), among which studies in outpatients have tended to show the drug superior to placebo while inpatient studies have not. Inpatients are likely to have more severe and more endogenous depressive symptoms than outpatients. There are also three positive studies in phobics. In a predictor study (Paykel et al., 1979) we found better response in outpatients less severely ill, not retarded, showing an admixture of anxiety symptoms and scoring at the atypical end of the Nies-Robinson Diagnostic Index. However, this was an open study without placebo or tricyclic comparison groups.

We therefore undertook a controlled trial in outpatient depressives (Paykel, 1982; Rowan et al., 1982). Overall both phenelzine and amitriptyline were superior to placebo. Both were quite useful in outpatient neurotic depressives of a kind often regarded as not responsive to drugs. When we looked at the symptoms which were predominantly affected by phenelzine these were core symptoms of depressed mood and depressed thought content. Both drugs were acting fairly similarly and as true antidepressants. Phenelzine did, in addition, have some small effects on anxiety.

We classified these patients in a variety of ways, reflecting the three different concepts of atypical depression, and looked for different drug responses. We found relatively little evidence of patients responding differentially and specifically to

\section{References}

ANDREASEN, N.C. (1982). Concepts, diagnosis and classification. In: Handbook of Affective Disorders, ed. Paykel,E.S.,pp. 24-44. Edinburgh:Churchill Livingstone. phenelzine or to amitriptyline rather than responding well to both drugs. There was some evidence that anxious patients responded well to phenelzine and those who were not anxious responded less well, but the effect was very weak. Chronic characterological depressives also tended to do poorly on phenelzine. However, amitriptyline was also clearly superior to placebo in anxious depressives although a little less so than phenelzine.

These findings are consistent with other evidence that the differences between the two types of drugs in clinically defined subgroups are weak at best. There is on the side of the tricyclics a considerable volume of studies showing that they are superior to placebo in outpatient neurotic depressives and increasing evidence that they are ineffective in severe deluded depressives (Paykel, 1979). Ravaris et al. (1980) recently found only weak differences between amitriptyline and phenelzine in symptom effects in anxious depressives. There is evidence that tricyclics are superior to placebo in agoraphobics (Sheehan et al., 1980; Zitrin et al., 1980), and in obsessional neuroses (Marks et al., 1980). Johnstone et al. (1980) found amitriptyline superior to placebo while diazepam was not, in mixed neurotic patients even with predominant anxiety.

\section{Conclusions}

The two most useful and widely accepted elements in the classification of depression remain the bipolar/unipolar dichotomy and the psychotic/neurotic dichotomy. Anxiety is a common symptom in depressed patients. There is evidence from multivariate statistical studies and in other ways, of the value of recognizing, at least loosely, those depressives who show marked anxiety. Such anxious depressives tend to lie predominantly, although not exclusively, in the neurotic rather than psychotic end of the spectrum. The picture regarding treatment is not as clear as it once seemed. Tricyclics may not be very effective in the more severely ill, anxious and agitated patients. There is stronger evidence that MAO inhibitors are of value in anxious depressed outpatients. In recent studies, however, there is clear evidence of the value of tricyclic antidepressants in outpatients with anxiety and depression.
ANGST, J. (1966). The Aetiology and Nosology of Endogenous Depressive Psychoses: A Genetic, Sociological and Clinical Study. Berlin: SpringerVerlag. 
GERSH, F.S. \& FOWLES, D.C. (1979). Neurotic depression: the concept of anxious depression. In: Psychobiology of Depressive Disorders, pp. 81-104.

HOLLISTER, L.E., OVERALL, J.E., JOHNSON, M.H., SHELTON, J., KIMBELL, I. \& BRUNSE, A. (1966). Amitriptyline alone and combined with perphenazine in newly admitted depressed patients. J. Nerv. Ment. Dis., 142, 460-469.

HOLLISTER, L.E., OVERALL, J.E., SHELTON, J., PENNINGTON, V., KIMBELL, I. \& JOHNSON, M. (1967). Drug therapy of depression amitriptyline, perphenazine and their combination in different syndromes. Arch. Gen. Psychiat., 17, 486-493.

JOHNSTONE, E.C., CUNNINGHAM OWENS, D.G., FRITH, C.D., MCPHERSON, K., DOWIE, C., RILEY, G. \& GOLD, A. (1980). Neurotic illness and its response to anxiolytic and antidepressant treatment. Psychol. Med., 10, 321-328.

KATZ, M.M., ROBINS, E., CROUGHAN, J., SECUNDA, S. \& SWANN, A. (1982). Behavioural measurement and drug response characteristics of unipolar and bipolar depression. Psychol. Med., 12, 25-36.

KENDELL, R.E. (1968). The classification of depressive illnesses. Maudsley Monogr., No. 18. London: Oxford University Press.

MARKS, I.M., STERN, R.S., MAWSON, D., COBB, J. \& MCDONALD, R. (1980). Clomipramine and exposure for obsessive-compulsive rituals, I. Br. J. Psychiat., 136, 1-25.

OVERALL, J.E., HOLLISTER, L.E., JOHNSON, M. \& PENNINGTON, V. (1966). Nosology of depression and differential response to drugs. J. Am. Med. Assoc., 195, 946-948.

OVERALL, J.E. \& RHOADES, H.M. (1982). Refinement of phenomenological classification in clinical psychopharmacology research. Psychopharmacol., 77, 24-30.

PAYKEL, E.S. (1971). Classification of depressed patients: a cluster analysis derived grouping. Br. J. Psychiat., 118, 275-288.

PAYKEL, E.S. (1972). Depressive typologies and response to amitriptyline. Br. J. Psychiat., 120, 147-156.

PAYKEL, E.S. (1979). Predictors of treatment response. In: Psychopharmacology of Affective Disorders, pp. 193-220. Oxford: Oxford University Press.

PAYKEL, E.S., ed. (1982). Life events and early environment. In: Handbook of Affective Disorders, pp. 146-161. Edinburgh: Churchill Livingstone.

PAYKEL, E.S. \& HENDERSON, A.L. (1977). Application of a cluster analysis in the classification of depression: a replication study. Neuropsychobiol., 3, 111-119.

PAYKEL, E.S., PARKER, R.R., PENROSE, R.J.J. \& RASSABY, E.R. (1979). Depressive classification and orediction of response to phenelzine. Br. J. Psychiat., 134, 572-581.

PAYKEL, E.S., PRUSOFF, B.A. \& KLERMAN, G.L. (1971). The endogenous-neurotic continuum in depression: rater independence and factor distributions. $J$. Psychiat. Res., 8, 73-90.
PAYKEL, E.S., ROWAN, P.R., RAO, B.M. \& BHAT, A. Atypical depression: nosology and response to antidepressants. In: Treatment of Depression: Old Controversies and New Approaches, ed. New York: Raven Press, in press.

PERRIS, C. (1966). A study of bipolar and unipolar recurrent depressive psychoses. Acta Psychiat. Scand., 42 (Suppl. 194).

PERRIS, C. (1982). The distinction between bipolar and unipolar affective disorders. In: Handbook of Affective Disorders, ed. Paykel, E.S., pp. 45-58. Edinburgh: Churchill Livingstone.

POLLITT, J. (1965). Depression and its Treatment. London: Heinemann.

PRUSOFF, B.A. \& PAYKEL, E.S. (1977). Typological prediction of responses to amitriptyline: a replication study. Int. Pharmacopsychiat., 12, 153-159.

QUITKIN, F.M., LIEBOWITZ, M. \& KLEIN, D.F Comparison of monoamine oxidase inhibitors and tricyclic antidepressants in the treatment of depression. In: Treatment of Depression: Old Controversies and New Approaches. New York: Raven Press, in press.

RAVARIS, C.L., ROBINSON, D.S., IVES, J.O., NIES, A. \& BARTLETT, D. (1980). Phenelzine and amitriptyline in the treatment of depression. Arch. Gen. Psychiat., 37, 1075-1080.

ROBINSON, D.S., NIES, A., RAVARIS, C.L., IVES, J.O. \& LAMBORN, K.R. (1974). Treatment response to MAO inhibitors: relation to depressive typology and blood platelet MAO inhibition. In: Classification and Prediction of Outcome of Depression, pp. 259-267. Stuttgart: Schattauer-Verlag.

ROSENTHAL, S.H. \& KLERMAN, G.L. (1966). Content and consistency in the endogenous depressive pattern. $B r$. J. Psychiat., 112, 471-484.

ROSENTHAL, S.H. \& GUDEMAN, J.E. (1967a). The endogenous depressive pattern: an empirical investigation. Arch. Gen. Psychiat., 16, 241-249.

ROSENTHAL, S.H. \& GUDEMAN, J.E. (1967b). The selfpitying constellation in depression. Br. J. Psychiat., 113, 485-489.

ROWAN, P.R., PAYKEL, E.S. \& PARKER, R.R. (1982). Phenelzine and amitriptyline: effects on symptoms of neurotic depression. Br. J. Psychiat., 140, 475-483.

SHEEHAN, D.V., BALLENGER, J. \& JACOBSEN, G. (1980). Treatment of endogenous anxiety with phobic, hysterical and hypochondriacal symptoms. Arch. Gen. Psychiat., 37, 51-59.

TYRER, P. (1976). Towards rational therapy with monoamine oxidase inhibitors. Br. J. Psychiat., 128, 354-360.

VAN PRAAG, H.M., ULEMAN, A.M. \& SPITZ, J.C. (1965). The vital syndrome interview. A structured standard interview for the recognition and registration of the vital depressive symptom complex. Psychiat. Neurol. Neurosurg., 68, 329-346.

WEST, E.D. \& DALLY, P.J. (1959). Effects of iproniazid in depressive syndromes. Br. Med. J., 1, 1491-1499.

ZITRIN, C.M., KLEIN, D.F. \& WOERNER, M.G. (1980). Treatment of agoraphobia with group exposure in vivo and imipramine. Arch. Gen. Psychiat., 37, 63-72. 